\title{
Anti-aging effects of Lasia spinosa L. stem extract on Drosophila melanogaster
}

\author{
Tran Thanh MEN ${ }^{1}$ (D), Do Tan KHANG ${ }^{2}$, Nguyen Trong TUAN ${ }^{1}$, Dai Thi Xuan TRANG ${ }^{1 *}$
}

\begin{abstract}
Anti-aging effect is a stimulating topic that attracting serious consideration from many researchers. Medicinal plants with anti-aging properties thereby have become common research subjects in various fields of science. This study aims to determine phytochemical constituents, specifically the total of phenolic and flavonoid contents and evaluate the anti-aging activity of ethanolic extracts from the stem of Lasia spinos $a$ L. The DPPH and ABTS assays were applied to investigate the in vitro antioxidant and free radical scavenging properties. Drosophila melanogaster Canton-S was used as the model organism to evaluate in vivo antioxidant activity, lifespan extension, climbing, and reproduction abilities. The results indicated that Lasia spinosa L. extract presented the phenolic and flavonoid contents, which were $271.65 \mathrm{mg} \mathrm{GAE} / \mathrm{g}$ and $579.57 \mathrm{mg} \mathrm{QE} / \mathrm{g}$, respectively. The EC values $_{50}$ of antioxidant activity was $23.80 \mu \mathrm{g} / \mathrm{mL}$ in DPPH assay and was $3.56 \mu \mathrm{g} / \mathrm{mL}$ for the assay of ABTS. The result also showed that the lifespan of adult fruit flies fed on extracts from Lasia spinosa L. was increased in oxidative stress conditions induced by $\mathrm{H}_{2} \mathrm{O}_{2}$. In lifespan assays, Drosophila melanogaster fed on the ethanolic extract from Lasia spinosa L. stem at $0.5 \mathrm{mg} / \mathrm{mL}$ of concentration in combination with standard food showed their mean lifespan increased to $22.9 \%, 50 \%$ survival increased to $22.2 \%$, and the maximum lifespan of last flies increased to $20.7 \%$ compared with the control. The research results demonstrated a potential property among its natural compounds of Lasia spinosa $\mathrm{L}$, which is capable of anti-aging through antioxidant activity in vitro and in vivo conditions.
\end{abstract}

Keywords: anti-aging; Drosophila melanogaster; Lasia spinosa L.; lifespan.

Practical Application: The potential use of Lasia spinosa L. extract for anti-aging.

\section{Introduction}

Aging is considered a significant manifestation of chronic diseases such as cancers, cardiovascular disease, diabetes, and various degenerative diseases (He \& Sharpless, 2017). Finding out strategies to support and keep up a long and healthy life as well as to expand an elderly population is a great challenge for scientists all over the world. Mechanistic studies of aging in many model organisms have provided theoretical insights into aging, especially the free radical theory of aging. This primary theoretical assumption deals with an imbalance in antioxidant defense and the levels of reactive oxygen species (ROS). Thus, the improvement of the antioxidant system and the decrease of ROS levels can basically prolong lifespan. Aging is an intrinsic and extrinsic process of a body, hence making it inappropriate for in vitro studies. In research of the aging process related to a human being, Drosophila melanogaster (D. melanogaster) may be a preferable choice among effective models for evaluating anti-aging compounds due to its incredibly favorable characteristics for biological research in genetics, physiology, microbial pathogenesis, and life history evolution. This model organism shares many conserved biological pathways and disease-causing genes in humans (Kim et al., 2011; Lee \& Min, 2019; Panchal \& Tiwari, 2017). In addition, D. melanogaster is a body of evidence for a fast and cost-effective model system in longevity research because of its characteristics of rapid lifespan, relatively simple genetics with only four pairs of chromosomes, and a large number of offsprings per generation.

There were various conspicuous case-in-points proving that for over 100 years, plant extracts have played a significant role in increasing lifespan in the field of traditional medicine of Vietnamese people. Lasia spinosa L. is known as an herbaceous plant that belongs to the family of Araceae. In Vietnam, this plant is widely used as a medicinal plant for the treatment of cough, inflammatory diseases, swollen lymph nodes, rheumatism, and injuries. In Lasia spinosa L. extracts, there are the presence of antioxidant properties, antimicrobial activities, cytotoxicity, and antihelminthic abilities (Goshwami et al., 2013; Shefana \& Ekanayake, 2010; Yadav, 2012). Rahman et al. (2019), indicated that the extracts of Lasia Spinosa L. contained an abundance of phenolic and flavonoid compounds. Its antioxidant constituents can combat oxidative stress through the free radical scavenging mechanism of phytochemicals such as vitamin E, vitamin C, flavonoids, and polyphenols (Pizzino et al., 2017). However, the effect of Lasia spinosa L. extracts on the lifespan of D. melanogaster has not been studied so far. This study aims to identify the mechanism of lifespan extension of fruit flies by using crude ethanol extract from Lasia spinosa L. stem in analyzing the phytochemical constituents, antioxidant effect, and investigate 
the longest living fruit flies through three evaluation criteria including maximum lifespan, $50 \%$ survival time and mean lifespan.

\section{Materials and methods}

\subsection{Preparation of Lasia spinosa L. extract (LSE)}

Lasia spinosa $\mathrm{L}$. stems were collected, rinsed with water, and shade dried at $50{ }^{\circ} \mathrm{C}$ in a dryer machine; after that, they were subjected to get fine powder by grinding using a mechanical grinder. By maceration for $24 \mathrm{~h}$, dried powdered stems (100g) were extracted with $1.0 \mathrm{~L}$ of $96 \%$ ethanol (India). Whatman filter paper No.1 (Camlab, UK) was applied to filter the solution. Used a rotary vacuum evaporator to evaporate the solvent at $50{ }^{\circ} \mathrm{C}$. The final extract (which is considered as LSE) was then lyophilized and stored for further analysis.

\subsection{Qualitative and quantitative analysis of phytochemical constituents}

Qualitative natural compounds from LSE were observed and reported by Jasuja et al. (2013). In this study, the compounds of alkaloid, saponin, flavonoids, phenolic, and tannins were tested. The total phenolic content was measured through Folin-Ciocalteu reagent (Merk, China), applying the method described by Singleton et al. (1999), while total flavonoid content was determined by the method in the description of Thitilertdecha et al. (2008).

\subsection{Determination of in-vitro antioxidant activity}

The antioxidant activity of LSE was determined using DPPH (Sigma, Germany) and ABTS (Sigma, China) methods. These two different scavenging methods were used with the same latex sample. While the DPPH was determined according to the method described by Sharma \& Bhat (2009), the ABTS assay process was mentioned in the description of Nenadis et al. (2004).

\subsection{Fly strain and culturing of Drosophila}

Fly stock applied was wild-type Drosophila melanogaster Canton-S (CS) (Bloomington Drosophila Stock Center, Department of Biology, Indiana University, Bloomington, USA). Fly stock was maintained on a standard diet containing agar, saccharose, dry yeast, and cornmeal. Specifically, $1000 \mathrm{~mL}$ of diet includes $50 \mathrm{~g}$ of cornmeal, $40 \mathrm{~g}$ of yeast, $100 \mathrm{~g}$ of saccharose, and $10 \mathrm{~g}$ of agar (Sigma, China). Propionic acid $(5 \mathrm{~mL})$ and sodium benzoate $(1 \mathrm{~g})$ (both from Sigma, China) were added to the diet to prevent mold growth. $15 \mathrm{~mL}$ of the standard diet was poured and set into the vials of maintained-fly stock, while $10 \mathrm{~mL}$ of the standard or experimental diets were prepared for experimental flies in each vial. Rearing conditions of fruit flies were maintained at $25 \pm 1.2{ }^{\circ} \mathrm{C}$, with a relative humidity of $70-80 \%$ and a photoperiod of 12:12 (light/dark).

\subsection{In vivo antioxidant assay}

The antioxidant assay was carried out according to Wongchum and Dechakhamphu's description (Wongchum \& Dechakhamphu, 2021). $\mathrm{H}_{2} \mathrm{O}_{2}$ was used for generating hydroxyl radical $(\cdot \mathrm{OH})$. The newly eclosed male fruit flies were reared in three different food conditions, including in the control diet, diet adding $0.5 \mathrm{mg} / \mathrm{mL}$ of LSE (20 per vial) and diet supplying $0.05 \mathrm{mg} / \mathrm{mL}$ gallic acid (GA) (Sigma, China), which was used as a positive control. On day 30, all three groups of the fruit flies were starved for $2 \mathrm{~h}$ in an empty vial containing filter paper soaked with distilled water. They were then transferred to separate vials containing a filter paper saturated with $10 \% \mathrm{H}_{2} \mathrm{O}_{2}$ (Sigma, China) which was prepared with $6 \%$ sucrose solution. Fly mortality was recorded every $4 \mathrm{~h}$ until the last fly was dead.

\subsection{Examine of LSE effects on reproduction of flies}

Add $0.5 \mathrm{mg}$ of LSE (LSE treatment) and $0.05 \mathrm{mg}$ gallic acid (GA treatment), respectively, in the standard food per milliliter to prepare LSE and GA diets. In order to examine its probable effect on the solvent used in preparing stock solutions of LSE and GA, an equivalent amount of $96 \%$ ethanol in the test sample was added to the culture medium administrated to the control group (control treatment). Fertilized female fruit flies of the same age (2-3 days) were placed in each treatment for $48 \mathrm{~h}$ to lay eggs. After $48 \mathrm{~h}$, the male and female flies were removed from the vials. The development of an organism named parental or " $\mathrm{P}$ " generation is present in vials. After their imaginal molt, the fruit flies were removed from vials. Next, adult females and males from "P" were transferred to another vial containing the same vial medium, separately. These flies were transferred to a fresh medium every two days. After 40 days, three adult females and three adult males were chosen to mate together. Mated flies laid eggs after mating overnight. The organism of first-generation (F1) completed their development were counted to analyzing the development and reproductive ability. Numbers of third instar larvae, pupae (visible on the surface of substrate and vial), and imagoes were counted throughout the test. The third instar larva, pupa, and adult stages in vials (time in days and the number that flies reached each stage) were calculated. These experiments on fruit flies were repeated five times along with control sets.

\subsection{Climbing assay}

The assay for the climbing ability of fruit flies was performed as described previously (Kyotani et al., 2016). After cultured in the food with or without LSE for 40 days, "P" male flies were placed in an empty $15 \mathrm{~cm}$ glass vial with a $2 \mathrm{~cm}$ diameter. The way to put the flies in the bottom is by tapping at the vials. The movements of flies were then measured for a duration of $15 \mathrm{~s}$. In all experiments for climbing ability, the height which each fly climbed was measured after $5 \mathrm{~s}$. Climbing ability was expressed as the distance from the bottom of the vail to the position in which flies climbed up on the vial. The reiteration for these procedures was carried out five times, and the experiment result was recorded by a digital camera.

\subsection{Lifespan assay}

This assay was mentioned by Zhang et al. (2014), newly eclosed male flies were separated and randomly divided into three vials (20 flies per vial) for each experiment. The control group was subjected to feed on standard food, and the other 
two groups were fed on standard food adding $0.5 \mathrm{mg} / \mathrm{ml}$ of LSE and D-galactose replaced for saccharose, respectively. Flies in three groups of experiments were transferred to fresh medium every three days. Its mortality was recorded until all flies died. The lifespan curve, mean lifespan, and maximal lifespan were obtained and calculated.

\subsection{Statistical analysis}

The mean \pm standard deviation was used to express the data collected from five-time determinations. The recorded data were treated statistically using a one-way analysis of variance (ANOVA). Statistical comparison of means followed by the Student's T-test with $\mathrm{p}<0.05$ considered to be statistically different. All statistical analysis was carried out by applying Minitab (Version 16) software.

\section{Results and discussion}

\subsection{Phytochemical contents}

The result demonstrated the existence of alkaloid, saponin, flavonoids, phenolic, and tannins compounds in LSE. A previous study indicated that plants produce secondary compounds belonging to phenolic, alkaloid, flavonoid, and tannin that present antioxidants in vitro and in vivo (Lee et al., 2004; Wu et al., 2011). Phenolic and flavonoid compounds have antioxidant activities, thus benefit human health, especially in curing and preventing many diseases (Tungmunnithum et al., 2018). This study showed that in LSE, there were a certain number of biological compounds with potential applications in antioxidant research. An outstanding of LSE was its phenolic content of $271.65 \pm 0.11 \mathrm{mg} \mathrm{GAE} / \mathrm{g}$ of extract (gallic acid equivalents per gram of extract) and flavonoid content of $579.57 \pm 12.62 \mathrm{mg} \mathrm{QE} / \mathrm{g}$ of extract (quercetin equivalents per gram of extract). Lasia spinosa L. leaves had also been studied for their phenolic content of $158 \pm 0.56 \mathrm{mg} \mathrm{GAE} / \mathrm{g}$ (Nguyen et al., 2020), which is much lower than in the stem. There was no flavonoid content mentioned in this previous study.

\subsection{Effect of LSE on the in vitro and in vivo oxidative stress resistance}

In this research, the DPPH and ABTS methods were used to evaluate the antioxidant activity in vitro of LSE. The data which were estimated expressed the $\mathrm{EC}_{50}$ values of LSE through each method. $\mathrm{EC}_{50}\left(\right.$ or $\left.\mathrm{IC}_{50}\right)$ value is a standard parameter used to examine the antioxidant capacity of substances or compounds. It is determined by the content of antioxidants needed to decrease the initial DPPH concentration by 50\% (Rivero-Cruz et al., 2020). The lowest $\mathrm{EC}_{50}$ indicates the most potent antioxidant activity. Those with an $\mathrm{EC}_{50}$ value of lower than $50 \mu \mathrm{g} / \mathrm{mL}$ indicate a very strong antioxidant; the $\mathrm{EC}_{50}$ value, which is from 50 to $100 \mu \mathrm{g} / \mathrm{mL}$, is considered as a sample with strong antioxidant, and from 101 to $150 \mu \mathrm{g} / \mathrm{mL}$ as a medium antioxidant sample while a weak antioxidant in the sample will be presented with the $\mathrm{EC}_{50}$ of over $150 \mu \mathrm{g} / \mathrm{mL}$ (Kusmardiyani et al., 2016). As presented in Table 1, the $\mathrm{EC}_{50}$ values of LSE in ABTS method was $3.56 \pm 0.06 \mu \mathrm{g} / \mathrm{mL}$, which was lower than its $\mathrm{EC}_{50}$ value of $23.80 \pm 0.60 \mu \mathrm{g} / \mathrm{mL}$ in
DPPH method. The $\mathrm{EC}_{50}$ of LSE through the two methods has also demonstrated its very strong antioxidant activity.

In in vivo analysis, flies fed on a diet supplying $0.5 \mathrm{mg} / \mathrm{mL}$ of LSE were monitored for their survival time. Figure 1 and Table 2 presented the experiment results that LSE had in vivo antioxidants in the $\mathrm{H}_{2} \mathrm{O}_{2}$ method. Under $\mathrm{H}_{2} \mathrm{O}_{2}$ condition, flies fed on LSE had a mean lifespan, 50\% survival, and $10 \%$ survival (also known as maximum lifespan and determined as the average lifespan of the $10 \%$ last surviving flies), which were $2.06,1.67$, and 1.57 times higher than the control, respectively. These values of mean lifespan, 50\% survival, and maximum lifespan in LSE treatment were lower than in GA treatment but without statistical significance $(p>0.05)$. This result was reasonable because GA is a standard commercial antioxidant with high purity. At the same time, medicinal extracts are highly synthetic extracts containing many different compounds that can act as mutual inhibitors (Mansouri et al., 2014). All in all, the study results provided evidence for the presence of antioxidant activity in LSE through in vitro and in vivo analysis.

Table 1. $\mathrm{EC}_{50}$ values of GA and LSE.

\begin{tabular}{crc}
\hline \multirow{2}{*}{ Sample } & \multicolumn{2}{c}{$\mathrm{EC}_{50}(\mu \mathrm{g} / \mathrm{mL})$} \\
\cline { 2 - 3 } & \multicolumn{1}{c}{$\mathrm{DPPH}$} & $\mathrm{ABTS}$ \\
\hline GA & $3.60 \pm 0.30$ & $0.40 \pm 0.01$ \\
LSE & $23.80 \pm 0.60$ & $3.56 \pm 0.06$ \\
\hline
\end{tabular}

Table 2. In vivo antioxidant effects of GA $(0.05 \mathrm{mg} / \mathrm{mL})$ and LSE $(0.5$ $\mathrm{mg} / \mathrm{mL}$ ) under $10 \% \mathrm{H}_{2} \mathrm{O}_{2}$ condition.

\begin{tabular}{cccc}
\hline Treatment & $\begin{array}{c}\text { Mean lifespan } \\
\text { (hour) }\end{array}$ & $\begin{array}{c}50 \% \text { survival } \\
\text { (hour) }\end{array}$ & $\begin{array}{c}\text { Maximum } \\
\text { lifespan (hour) }\end{array}$ \\
\hline Control & $21.00^{\mathrm{c}} \pm 1.0$ & $26.33^{\mathrm{b}} \pm 0.58$ & $40.33^{\mathrm{b}} \pm 0.58$ \\
GA & $47.00^{\mathrm{a}} \pm 1.0$ & $46.00^{\mathrm{a}} \pm 1.0$ & $60.33^{\mathrm{a}} \pm 0.58$ \\
LSE & $43.20^{\mathrm{ab}} \pm 1.58$ & $44.00^{\mathrm{a}} \pm 1.73$ & $63.33^{\mathrm{a}} \pm 0.58$ \\
\hline
\end{tabular}

Means $(n=5)$ presented in different letters differ significantly at $\mathrm{p}<0.05$.

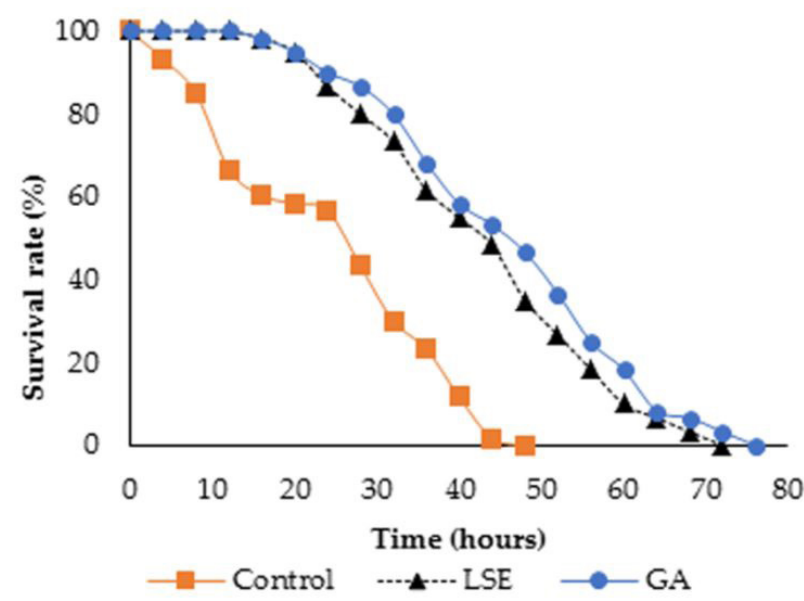

Figure 1. Effect of hydrogen peroxide on lifespan curve of wild-type CS flies fed on standard food (control), $0.05 \mathrm{mg} / \mathrm{mL} \mathrm{GA}$, and $0.5 \mathrm{mg} / \mathrm{mL}$ LSE. Data were expressed as the maximum lifespan of the $10 \%$ last fly, $50 \%$ survival time, and mean lifespan for each group (Table 2). 


\subsection{LSE effect on reproduction of D. melanogaster}

The research results of the effects of LSE on the reproduction of 40-day-old D. melanogaster were presented in Table 3.

The reproductive output is physiology-related criteria for survey the aging. In Drosophila, long-lived flies lead to their decrease of reproduction (Sun et al., 2013). In this study, we had 40-day-old male and female D. melanogaster mated to observe the reproduction ability. The result showed the different development stages of flies, including third-instar larvae, pupae, and adult. The result in Table 3 showed the appearance period of the third instar larvae, pupae, and adult is not different between the treatments when fruit flies were raised at the same ambient conditions of $25^{\circ} \mathrm{C}$. However, at the pupae stage, flies fed on GA supplementary had a total number of pupae recorded after ten days of $149.00 \pm 4.58$, which was the highest and was significantly different compared to its on LSE and control. The number of third instar larvae transforming to pupae after ten days of the LSE experiment is $76.68 \pm 3.51$ offsprings, significantly different from the control treatment of $63.67 \pm 3.51$ offsprings. The research results also recorded the number of pupae that transformed into adult flies after 14 days was similar to the number of pupae after ten days of the experiment. From the research result, it can be assumed that LSE at the concentration of $0.5 \mathrm{mg} / \mathrm{ml}$ of the food supplement is capable of improving health expressed by the ability to improve the reproduction of CS fruit flies. Experimental results showed that the reproduction and the development of fruit flies raised with higher GA supplement over control and LSE was appropriate because GA is a commercial antioxidant with high purity and has been used as for positive control in many

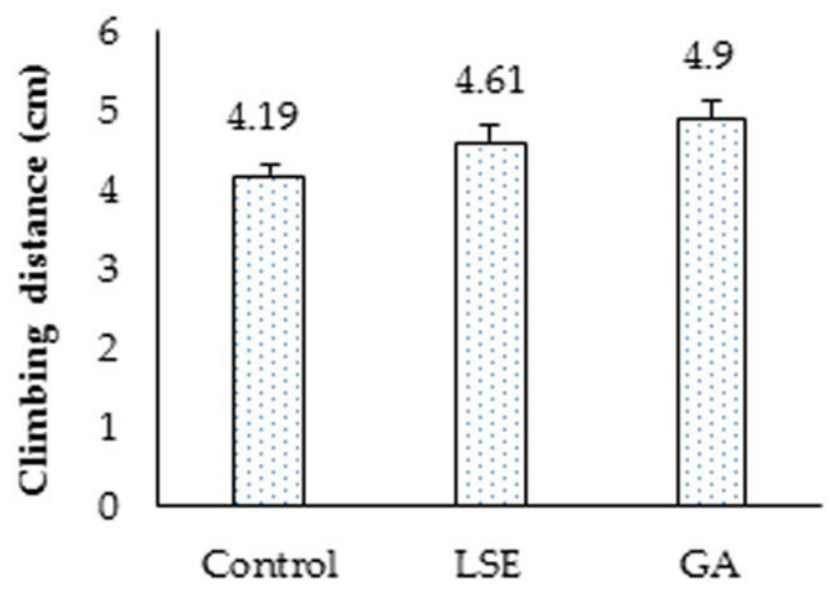

\section{Treatments}

Figure 2. Effect of LSE on climbing ability of D. melanogaster. previous studies (Ortega-Arellano et al., 2013). LSE contains antioxidant compounds that are flavonoid and phenolic. In addition, LSE has antioxidant capacity in vitro through DPPH and ABTS methods (Table 1), has effective antioxidant capacity in vivo conditions on fruit flies expressed in the $\mathrm{H}_{2} \mathrm{O}_{2}$ method (Table 2 and Figure 1). Thus it might argue that the effectiveness of improving the reproduction and development of LSE is due to the presence of flavonoids and phenolic in Lasia spinosa $\mathrm{L}$. through their oxidation resistance.

\subsection{LSE improved climbing ability}

The result identifying movement ability of 40-day-old male fruit flies raised in the conditions of control, LSE and GA were presented in Figure 2. The movement ability of fruit flies in experiments was recorded and presented as a distance $(\mathrm{cm})$ of moving up in the first $5 \mathrm{~s}$ after tapping the vials to cause the flies to fall to the bottom.

Movement ability is one of the indicators to survey for antiaging assessment of pharmaceutical materials. Pharmaceuticals with good anti-aging activity will possibly improve the movement ability of fruit flies (Arabit et al., 2018). Figure 2 showed that the movement ability of 40-day-old fruit flies raised in the conditions of control, LSE, and GA reached $4.19 \mathrm{~cm}, 4.61 \mathrm{~cm}$, and $4.9 \mathrm{~cm}$, respectively. Accordingly, the movement ability of fruit flies raised in the environment adding $0.05 \mathrm{mg} / \mathrm{mL}$ of GA increased by $17 \%$; in the environment adding $0.5 \mathrm{mg} / \mathrm{mL}$ of LSE increased by $10 \%$ compared to those raised in standard food (control) environment. The physiological function declining by age is the main cause of illness and death by age. Therefore, maintaining physiological function in aging is essential to prolong human health (Seals \& Melov, 2014).

\subsection{Effect of LSE on longevity of wild-type CS flies}

The present study demonstrated that LSE had a beneficial effect on the lifespan of D. melanogaster. The effect of D-galactose and LSE were showed in Figure 3 and Table 4. As shown in Table 4, the D-galactose group had a mean lifespan of $34.75 \pm 1.15$ days; LSE and control groups had a mean lifespan of $49.10 \pm 2,39.95 \pm 1.06$, respectively. Supplementation with a $0.5 \mathrm{mg}$ L.S.E./mL diet significantly increased the mean lifespan by $22 \%$ compared with that of the control group. The mean lifespan of the D-galactose group was shorter than that of the control group, and a significant difference was observed. The $50 \%$ survival time of wild-type CS flies reared with D-galactose diet was $36.67 \pm 0.58$ days, while that of the LSE diet and the control were $51.33 \pm 2.08$ days and $42.00 \pm 2$ days, respectively. LSE experiment significantly extended the $50 \%$ survival time of wild-type CS flies while D-galactose showed decreased

Table 3. Effect of GA and LSE on development and reproduction of D. melanogaster.

\begin{tabular}{|c|c|c|c|c|c|c|}
\hline \multirow[b]{2}{*}{ Treatment } & \multicolumn{2}{|c|}{ Third instar larvae } & \multicolumn{2}{|c|}{ Pupae stage } & \multicolumn{2}{|c|}{ Adult stage } \\
\hline & $\begin{array}{c}\text { Reached time } \\
\text { (day) }\end{array}$ & $\begin{array}{c}\text { Number after } \\
5 \text { days }\end{array}$ & $\begin{array}{c}\text { Reached time } \\
\text { (day) }\end{array}$ & Number after 10 days & $\begin{array}{c}\text { Reached time } \\
\text { (day) }\end{array}$ & Number after 14 days \\
\hline Control & 5 & $12 \pm 0.58$ & 7 & $63.67^{c} \pm 3.51$ & 10 & $63.33^{c} \pm 3.06$ \\
\hline LSE & 5 & $12 \pm 0.58$ & 7 & $76.68^{\mathrm{b}} \pm 3.51$ & 10 & $76.67^{\mathrm{b}} \pm 3.51$ \\
\hline
\end{tabular}




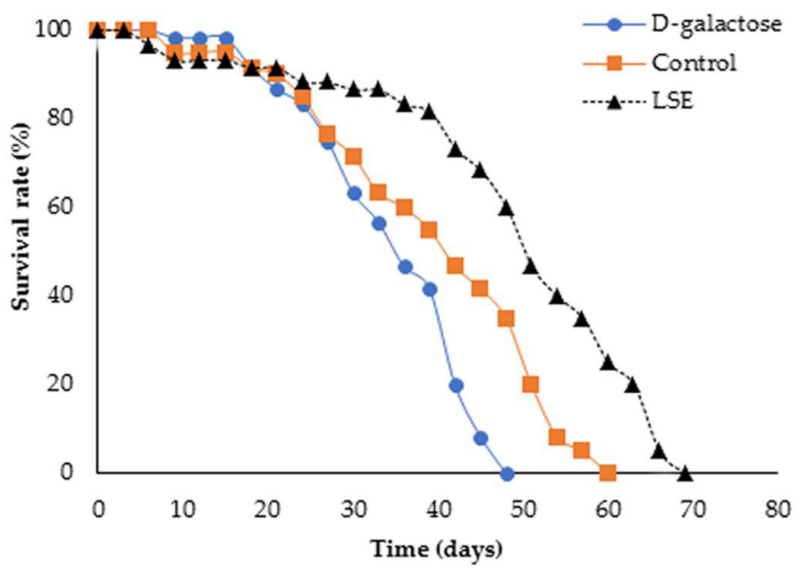

Figure 3. Lifespan curve of wild-type CS flies fed with basal diet (control), $0.5 \mathrm{mg} / \mathrm{mL}$ of LSE, and D-galactose (replace for saccharose). Data were expressed as the maximum lifespan of the $10 \%$ last flies, $50 \%$ survival time, and mean lifespan for each group. The results showed $0.5 \mathrm{mg} \mathrm{LSE} / \mathrm{mL}$ could significantly extend the maximum lifespan of wild-type CS flies $(\mathrm{p}<0.05)$.

Table 4. Effect of LSE on the survival time of CS wild type flies fed with the control diet.

\begin{tabular}{cccc}
\hline Treatment & $\begin{array}{c}\text { Mean lifespan } \\
\text { (days) }\end{array}$ & $\begin{array}{c}50 \% \text { survival } \\
\text { (days) }\end{array}$ & $\begin{array}{c}\text { Maximum lifespan } \\
\text { (days) }\end{array}$ \\
\hline Control & $39.95^{\mathrm{b}} \pm 1.06$ & $42.00^{\mathrm{b}} \pm 2.00$ & $54.67^{\mathrm{b}} \pm 2.52$ \\
D-galactose & $34.75^{\mathrm{c}} \pm 1.15$ & $36.67^{\mathrm{c}} \pm 0.58$ & $45.67^{\mathrm{c}} \pm 0.58$ \\
LSE & $49.10^{\mathrm{a}} \pm 2.00$ & $51.33^{\mathrm{a}} \pm 2.08$ & $66.00^{\mathrm{a}} \pm 2.00$ \\
\hline
\end{tabular}

Means $(n=5)$ presented in different letters differ significantly at $\mathrm{p}<0.05$.

$(\mathrm{p}<0.05)$. In addition, the control treatment reached a maximum lifespan of $54.67 \pm 2.52$ days fed on a standard diet higher than the $\mathrm{D}$-galactose $(45.67 \pm 0.58$ days $)$, whereas when the dosage of LSE was increased, the maximum lifespan of the wild-type CS flies reached $66.00 \pm 2.00$ days. The maximum lifespan increased more than 11.33 days in the $0.5 \mathrm{mg}$ LSE/ $\mathrm{mL}$ group compared to the control one and with a significant difference $(\mathrm{p}<0.05)$.

Cui et al. (2004) demonstrated that D-galactose caused rapid aging and shortened lifespan of fruit flies. In this research, wild-type CS flies were fed on the condition of adding D-galactose and LSE to observe their effects on the lifespan of D. melanogaster compared to those fed in standard food. As shown in Table 4, flies raised in the condition of adding D-galactose had a mean lifespan of $34.75 \pm 1.15$ days; LSE and control groups had a mean lifespan of $49.10 \pm 2.00$ days, $39.95 \pm 1.06$ days, respectively. Supplementation with a $0.5 \mathrm{mg} \mathrm{LSE} / \mathrm{mL}$ diet significantly increased the mean lifespan by $22 \%$ compared to the control group. The mean lifespan of the $\mathrm{D}$-galactose group was shorter than the control group, and a significant difference was observed $(\mathrm{p}<0.05)$. The $50 \%$ survival time of wild-type CS flies fed on $\mathrm{D}$-galactose diet was $36.67 \pm 0.58$ days, while the LSE diet and the control had a $50 \%$ survival time of $51.33 \pm 2.08$ days, $42.00 \pm 2.00$ days, respectively. LSE treatment significantly extended the $50 \%$ survival time of wild-type CS flies, whereas it is decreased in D-galactose treatment $(\mathrm{p}<0.05)$. In addition, the control treatment reached $54.67 \pm 2.52$ days of maximum lifespan, higher than the $\mathrm{D}$-galactose, which was $45.67 \pm 0.58$ days, whereas, at the condition of adding LSE, the maximum lifespan of the wild-type CS flies reached $66.00 \pm 2.00$ days. The maximum lifespan increased more than 11.33 days in LSE group compared to the control and with a significant difference $(p<0.05)$. The experimental results of raising flies in the food supplement with D-Galactose fully match the mentioned research. In addition, the research results showed that fruit flies raised in the LSE group have mean lifespan increased by $22.9 \%, 50 \%$ survival increased by $22.2 \%$, and maximum lifespan increased by $20.7 \%$ compared to flies raised in the basal diet. Thus it can be stated that LSE at a concentration of $0.5 \mathrm{mg} / \mathrm{ml}$ has the anti-aging ability through longevity extension effects on Drosophila melanogaster. Moreover, the ability of lifespan extension of LSE is considered to be more effective than the extracts from blueberry. Fruit flies, feeding on food with the extracts from blueberry at a concentration of $5 \mathrm{mg} / \mathrm{mL}$, had a longer mean lifespan which was $10 \%$ higher than those in the control environment (Peng et al., 2012); those fed on higher vitamin $\mathrm{E}$ at a concentration of $20 \mu \mathrm{g} / \mathrm{mL}$, had a mean lifespan increased to $16 \%$ compared to the control (though there is no effect at higher or lower concentrations) (Driver \& Georgeou, 2003); flies with $\mathrm{N}$-acetylcysteine antioxidant (NAC) at $1 \mathrm{mg} / \mathrm{mL}$ had $16,6 \%$ higher mean lifespan compared to the control (Brack et al., 1997); whereas fruit flies fed on the extracts of brown rice at $30 \mathrm{mg} / \mathrm{mL}$ can extend their mean lifespan of fruit flies by 14\% (Zuo et al., 2012).

The research results on lifespan extension of LSE showed that the survival time values increased and differed significantly compared to the control. This result matched perfectly with the experiments on chemical composition and antioxidant activity of LSE, thereby stating that the anti-aging property (lifespan extension) on fruit flies of LSE is due to many pharmacological ingredients with an effective stress-oxygen resistance ability, which are antioxidants including phenolic and flavonoids. Antioxidants can neutralize the inactivation of free radicals, inhibit activities or inhibit the expression of genes that specify enzymes creating free radicals such as NADPH oxidase and xanthine oxidase, and enhance the activity and the manifestation of genes regulating oxidative enzymes such as SOD, C.A.T., GPx, Rpn11. This issue on its mechanism needs further studies.

\section{Conclusions}

Even if further experiments on the mechanism were carried out, we would like to emphasize that adding LSE in food media could prolong the lifespan, alleviate climbing ability and maintain the reproduction in $D$. melanogaster model. The anti-aging activity of LSE was at least partially associated with its antioxidant activities of a chemical compound from LSE.

\section{Conflicts of interest}

The authors declare no conflict of interest.

\section{Funding}

This research was under the funding by the Vietnam Ministry of Education and Training (MOET), project number: B2019-TCT-01. 


\section{Author contributions}

Conceptualization, TTM and DTXT; methodology, TTM and DTK; formal analysis, TTM and NTT; investigation, TTM, DTK and NTT; resources, TTM and DTXT; supervision, DTXT; writing, review and editing, TTM, DTK, NTT and DTXT. All authors have read and agreed to the published version of the manuscript.

\section{Acknowledgments}

We are grateful to Professor Kamei Kaeko, Department of Biomolecular Engineering, Kyoto Institute of Technology, Japan, for providing the Drosophila melanogaster Canton-S.

\section{References}

Arabit, J. G. J., Elhaj, R., Schriner, S. E., Sevrioukov, E. A., \& Jafari, M. (2018). Rhodiola rosea improves lifespan, locomotion, and neurodegeneration in a Drosophila melanogaster model of Huntington's disease. BioMed Research International, 2018, 6726874.

Brack, C., Bechter-Thüring, E., \& Labuhn, M. (1997). N-Acetylcysteine slows down ageing and increases the life span of Drosophila melanogastar. Cellular and Molecular Life Sciences, 53(11-12), 960-966. PMid:9447249.

Cui, X., Wang, L., Zuo, P., Han, Z., Fang, Z., Li, W., \& Liu, J. (2004). D-Galactose-caused life shortening in Drosophila melanogaster and Musca domestica is associated with oxidative stress. Biogerontology, 5(5), 317-325. http://dx.doi.org/10.1007/s10522-004-2570-3. PMid:15547319.

Driver, C., \& Georgeou, A. (2003). Variable effects of vitamin E on Drosophila longevity. Biogerontology, 4(2), 91-95. http://dx.doi. org/10.1023/A:1023347803932. PMid:12766533.

Goshwami, D., Rahman, M., Muhit, M., Islam, M., \& Anasri, M. (2013). Antioxidant property, cytotoxicity and antimicrobial activity of Lasia spinosa leaves. Nepal Journal of Science and Technology, 13(2), 215-218. http://dx.doi.org/10.3126/njst.v13i2.7739.

He, S., \& Sharpless, N. E. (2017). Senescence in health and disease. Cell, 169(6), 1000-1011. http://dx.doi.org/10.1016/j.cell.2017.05.015. PMid:28575665.

Kim, S. I., Jung, J. W., Ahn, Y. J., Restifo, L. L., \& Kwon, H. W. (2011). Drosophila as a model system for studying lifespan and neuroprotective activities of plant-derived compounds. Journal of Asia-Pacific Entomology, 14(4), 509-517.

Kusmardiyani, S., Novita, G., \& Fidrianny, I. (2016). Antioxidant activities from various extracts of different parts of kelakai (Stenochlaena palustris) grown in central Kalimantan - Indonesia. Asian Journal of Pharmaceutical and Clinical Research, 9, 215-219.

Kyotani, A., Azuma, Y., Yamamoto, I., Yoshida, H., Mizuta, I., Mizuno, T., Nakagawa, M., Tokuda, T., \& Yamaguchi, M. (2016). Knockdown of the Drosophila FIG4 induces deficient locomotive behavior, shortening of motor neuron, axonal targeting aberration, reduction of life span and defects in eye development. Experimental Neurology, 277, 86-95.

Lee, J., Koo, N., \& Min, D. B. (2004). Reactive oxygen species, aging, and antioxidative nutraceuticals. Comprehensive Reviews in Food Science and Food Safety, 3(1), 21-33. http://dx.doi.org/10.1111/j.1541-4337.2004. tb00058.x. PMid:33430557.

Lee, S. H., \& Min, K. J. (2019). Drosophila melanogaster as a model system in the study of pharmacological interventions in aging. Translational Medicine of Aging, 3, 98-103.
Mansouri, M. T., Soltani, M., Naghizadeh, B., Farbood, Y., Mashak, A., \& Sarkaki, A. (2014). A possible mechanism for the anxiolytic-like effect of gallic acid in the rat elevated plus maze. Pharmacology Biochemistry and Behavior, 117, 40-46.

Jasuja, N. D., Sharma, S. K., Saxena, R., Choudhary, J., Sharma, R., \& Joshi, S. C. (2013). Antibacterial, antioxidant and phytochemical investigation of Thuja orientalis leaves. Journal of Medicinal Plants Research, 7(25), 1886-1893.

Nenadis, N., Wang, L. F., Tsimidou, M., \& Zhang, H. Y. (2004). Estimation of scavenging activity of phenolic compounds using the ABTS.+ assay. Journal of Agricultural and Food Chemistry, 52(15), 4669-4674. http://dx.doi.org/10.1021/jf0400056. PMid:15264898.

Nguyen, T. Q. C., Duy Binh, T., Pham, T. L. A., Nguyen, Y. D. H., Thi Xuan Trang, D., Nguyen, T. T., Kanaori, K., \& Kamei, K. (2020). Anti-inflammatory effects of Lasia spinosa leaf extract in lipopolysaccharide-induced RAW 264.7 macrophages. International Journal of Molecular Sciences, 21(10), 3439. http://dx.doi.org/10.3390/ ijms21103439. PMid:32414062.

Ortega-Arellano, H. F., Jimenez-Del-Rio, M., \& Velez-Pardo, C. (2013). Dmp53, basket and drICE gene knockdown and polyphenol gallic acid increase life span and locomotor activity in a Drosophila Parkinson's disease model. Genetics and Molecular Biology, 36(4), 608-615. http://dx.doi.org/10.1590/S1415-47572013000400020. PMid:24385865.

Panchal, K., \& Tiwari, A. K. (2017). Drosophila melanogaster "a potential model organism" for identification of pharmacological properties of plants/plant-derived components. Biomedicine and Pharmacotherapy, 89, 1331-1345.

Peng, C., Zuo, Y., Kwan, K. M., Liang, Y., Ma, K. Y., Chan, H. Y. E., Huang, Y., Yu, H., \& Chen, Z. Y. (2012). Blueberry extract prolongs lifespan of Drosophila melanogaster. Experimental Gerontology, 47(2), 170178. http://dx.doi.org/10.1016/j.exger.2011.12.001. PMid:22197903.

Pizzino, G., Irrera, N., Cucinotta, M., Pallio, G., Mannino, F., Arcoraci, V., Squadrito, F., Altavilla, D., \& Bitto, A. (2017). Oxidative stress: harms and benefits for human health. Oxidative Medicine and Cellular Longevity, 2017, 8416763.

Rahman, A., Siddiqui, S. A., Oke-Altuntas, F., Okay, S., Gül, F., \& Demirtas, I. (2019). Phenolic profile, essential oil composition and bioactivity of Lasia spinosa (L.) thwaites. Brazilian Archives of Biology and Technology, 62, e19170757.

Rivero-Cruz, J. F., Granados-Pineda, J., Pedraza-Chaverri, J., PérezRojas, J. M., Kumar-Passari, A., Diaz-Ruiz, G., \& Rivero-Cruz, B. E. (2020). Phytochemical constituents, antioxidant, cytotoxic, and antimicrobial activities of the ethanolic extract of mexican brown propolis. Antioxidants, 9(1), 70.

Seals, D. R., \& Melov, S. (2014). Translational geroscience: emphasizing function to achieve optimal longevity. Aging, 6(9), 718-730. http:// dx.doi.org/10.18632/aging.100694. PMid:25324468.

Sharma, O. P., \& Bhat, T. K. (2009). DPPH antioxidant assay revisited. Food Chemistry, 113(4), 1202-1205. http://dx.doi.org/10.1016/j. foodchem.2008.08.008.

Shefana, A. G., \& Ekanayake, S. (2010). Some nutritional aspects of Lasia spinosa (kohila). Vidyodaya Journal of Science, 14, 59-64.

Singleton, V. L., Orthofer, R., \& Lamuela-Raventós, R. M. (1999). Analysis of total phenols and other oxidation substrates and antioxidants by means of folin-ciocalteu reagent. Methods in enzymology, 299, 152-178.

Sun, Y., Yolitz, J., Wang, C., Spangler, E., Zhan, M., \& Zou, S. (2013). Aging studies in Drosophila melanogaster. Methods in Molecular Biology, 1048, 77-93. http://dx.doi.org/10.1007/978-1-62703-5569_7. PMid:23929099. 
Thitilertdecha, N., Teerawutgulrag, A., \& Rakariyatham, N. (2008). Antioxidant and antibacterial activities of Nephelium lappaceum L. extracts. $L W T, 41(10), 2029-2035$. http://dx.doi.org/10.1016/j. lwt.2008.01.017.

Tungmunnithum, D., Thongboonyou, A., Pholboon, A., \& Yangsabai, A. (2018). Flavonoids and other phenolic compounds from medicinal plants for pharmaceutical and medical aspects: an overview. Medicines, 5(3), 93. http://dx.doi.org/10.3390/medicines5030093. PMid:30149600.

Wongchum, N., \& Dechakhamphu, A. (2021). Ethanol extract of Cassia siamea L. increases life span in Drosophila melanogaster. Biochemistry and Biophysics Reports, 25, 100925.

Wu, Y., Li, W., Xu, Y., Jin, E., \& Tu, Y. (2011). Evaluation of the antioxidant effects of four main theaflavin derivatives through chemiluminescence and DNA damage analyses. Journal of Zhejiang University Science. B., 12(9), 744-751. http://dx.doi.org/10.1631/jzus. B1100041. PMid:21887850.

Yadav, A. K. (2012). Efficacy of Lasia spinosa leaf extract in treating mice infected with Trichinella spiralis. Parasitology Research, 110(1), 493-498.

Zhang, Z., Han, S., Wang, H., \& Wang, T. (2014). Lutein extends the lifespan of Drosophila melanogaster. Archives of Gerontology and Geriatrics, 58(1), 153-159. http://dx.doi.org/10.1016/j.archger.2013.07.007. PMid:23993264.

Zuo, Y., Peng, C., Liang, Y., Ma, K. Y., Yu, H., Edwin Chan, H. Y., \& Chen, Z. Y. (2012). Black rice extract extends the lifespan of fruit flies. Food \& Function, 3(12), 1271-1279. http://dx.doi.org/10.1039/ c2fo30135k. PMid:22930061. 